\title{
The Effect High School Policies Have on a Students Comfort Levels When Talking About Race
}

\author{
Aditi Kanaujia \\ Dallas, Texas \\ Email-akanaujia8@gmail.com
}

\begin{abstract}
Racial discussions have always been an avoided topic by Americans, typically in fear of starting controversy. Starting as a country divided by race and color, America is beginning to grow in its acceptance of race. Due to this, in school systems, topics such as race along with racial conflicts are being integrated slowly into the classroom curriculum and discussions. This study evaluates the effect race-based policies in schools have on a student's ability (in terms of comfort) to discuss and address topics regarding racial stereotypes, bias, and racism within a classroom context, in Frisco Independent School District (FISD) high schools. This analysis will be conducted through the uses of surveys with differing questions targeted towards the two primary stakeholders of this issue: teachers and students, in which results will be summarized numerically to give conclusive results. The main purpose of this study is to highlight the possible need for a better way of integrating racial acceptance and equality within a classroom context. In contrast, if my study proves that FISD high schools effectively handle race in their curriculum, this school district can serve as a model for other districts to reach that same comfort of racial discussions amongst students and teachers.
\end{abstract}

Published by IJRP.ORG. Selection and/or peer-review under responsibility of International Journal of Research Publications (IJRP.ORG)

Keywords: Type your keywords here, separated by semicolons ;

\section{Literature Review}

Prior research in this field of study has indicated the importance of race in school curriculum. Therefore, this literature review will study the possible correlation between race embedment in the school curriculum, a student's comfort when talking about race, and how it affected the racial policies associated with my study.

\subsection{The Evolution of Race in American School Systems}

The learning of race and conducting racial discussions in high school was not always part of the norm in America. Beginning in 1820, the first public high school was opened in Boston, the U.S. but at this point, schools were only accommodating to white people and in southern states; teaching slaves' literature and other education were forbidden ("Historical Timeline" 2006). By 1877, African Americans were finally able to "push for many political changes, including...the first-time rewriting state constitutions to guarantee free 
public education to all races" however, white children still reaped more educational benefits than other races ("Historical Timeline" 2006). Even with this new addition, the educational system of America still lacked the embedding of race in school systems. During this time, white privilege led to increased racism toward African American kids, along with a smaller portion of other race children. This led to low attendance rates by children who were not white until the 1960s when Black Activism was at its peak ("History of Black Education" 2020). Once black education became more common Sociologist Jacqueline Fleming, an internationally known sociologist that studies minority students and psychology of different races, "discovered that...black students chose white institutions because of better academic reputations... and academic resources...[however,] the presence of racism or an environment that is hostile impedes these benefits for blacks. Fleming's studies show that black students tend to perform better and exhibit more personal growth at historically black institutions" ("History of Black Education" 2020).

Some questions that can be brought up now is whether race and the learning of race advances the educational capacity of students since white schools did not teach about any other cultures at the time except their own. Furthermore, in black institutions students were freely able to talk about race without hesitance about seeming racist or facing racism but in a white institution even teachers might be receptive to addressing these issues. Over time these issues became prevalent with other races as more moved into America. Of course, there may be several other factors that may play a role but there is a possibility to consider in which this paper will proceed to examine.

\subsection{The Current Trends of Race in School Policies}

Currently, the issue of racism and equality is of lower importance in comparison to earlier years so interactions amongst peers of differing race is a norm in many high schools across the United States. Yet even today "telling the truth about slavery in American public schools has long been a failing proposition." (Heim 2019). Due to such issues, some students are still feeling uncomfortable talking about their own and other races. According to Lawrence Blum, a distinguished Professor of Liberal Arts and Education at the University of Massachusetts who writes many scholarly works about race, there is a notable trend that "Americans, especially white Americans, don't like to talk about race... Many Americans think we are in a 'post-racial' society, partly because a black man is a president, so they don't need to give much thought to race anymore" or he asserts that it could also be due to the lack of knowledge (Blum 2012). Therefore, talking about race and teaching it to students is a very crucial part of enhancing a student's knowledge. Blum further verifies how “"Things racial' are not just matters of opinion and feeling. They are also mattering of knowledge and insight." proving the importance of increasing students' comfort levels when discussing this sensitive topic (Blum 2012). Also, teaching race in the correct manner is of the essence as many schools approach the issue using the colorblind method, which is "teaching children that it is racist to acknowledge racial and ethnic differences" (Whitman 2020). In other words, students are taught to not see a person by their color, however, that also means ignoring culture distinctions. Stacy Whitman, a publisher and founder of Tu Books (a New York based publishing company) and writers about anything nonfiction, diversity, literary, and history based, establishes a value for this issue "Teaching children to be 'colorblind' has led children (and adults) to believe that it's rude or racist to even point out racial differences...This makes it exponentially harder to have frank discussions about racial issues..." which further brings light to how important it is for the methods of how race is addressed in schools (Whitman 2020). Since the study focuses on the Frisco Independent School District (FISD) it is vital to see what policies directly affect the studied topic and the demographics of students. Coming straight from the FISD handbook, the main and more influential policies affecting students are racial discussions in schools and its filtering, zero tolerance for racism along with the consequences that follow, and the district belief system (which includes right of own beliefs and equal treatment). In addition, there are also policies filtering the involvement of race in curriculum and through online resources ("Frisco ISD Student 
Handbook" 2020). Connecting the letter of Blum, the FISD Handbook, and Whitman's study there are several possible correlations between the three. First of all, how well are the policies that FISD proposed embedded, and is it possible that they filter race too much or too less? Does it aid or limit a student's growth in understanding racial trends?

Finally, when overviewing the process of the parties or stakeholders involved in this topic the main people influenced or influencing are students and teachers. Of course, there are parents and higher education administration but when studying this topic, the most addressed through research are the two stakeholders mentioned.

Therefore, this study will focus on finding out whether or not FISD high schools have effective policies set in place to address racial stereotypes and biases. The reason this study focuses on FISD high schools is that this school district has very diverse schools so the study will focus on how education systems handle such ethnic complexes. According to the FISD online stats, $41.23 \%$ are white, 29.2\% are Asian, 13.50\% are Hispanic, $11.4 \%$ are African American, $4.22 \%$ are two or more races, and finally .61\% are other ("Frisco ISD" 2020). So, as all sources signified the importance and current trend none focused on one school district (specifically FISD) and conducted a study on the perspectives of students and teachers. Hence, this research paper will be examining this trend and possible correlation along with the possible implication brought upon.

Many schools do not face a major threat to this issue. In fact, there is already a pre-existing model for a racial educational framework, a school known as the HGSE Dissertation Fellowship for colored students to exercise the growth of racial acceptance. Aaliyah El-Amin, a practitioner along with a researcher who works to create school models such as HGSE Dissertation Fellowship, provide tools, and more to decrease racial disparity in schools, conducted a study in which she found out the 5 key principles to which every school should use as a framework "Sound racial identity, or to see one's racial identity as a strength and asset. Critical consciousness, or the ability to identify and deconstruct issues of inequity. Critical academic achievement identity, or the ability to link academic achievement with navigating society and transforming it. Collective obligation, or a sense of responsibility to a group. Activism skills, or ability to create and sustain systemic change." which was written in a Harvard article by Jill Anderson, who specializes in communication and marketing and is the senior digital content creator for Harvard university (Anderson 2014). However, her study along with prior studies do not study specific high schools' abilities to implement effective race policies and therefore, this study will focus on filling that knowledge gap for FISD schools.

\section{Methodology}

This study utilizes a survey containing targeted questions and a thematic analysis through the mixed methods, which is the "systematic integration or 'mixing,' of quantitative and qualitative data within a single investigation or sustained program of inquiry" to test the hypotheses (Wisdom 2013). Survey research is "independent and dependent variables that are used to define the scope of study" (Glasow 2015). This research is a focused analysis of two surveys, one from students and the other from teachers from FISD high schools. The use of two surveys provides insight along with a wide variety of perspectives regarding the extent to which school factors affect students' racial discussions in school. Furthermore, the questions are tailored to pull both qualitative and quantitative data from respondents' answers to test my hypothesis: racial policies in FISD do limit racial discussion and comfort of students.

This setup is modeled after the combination of two studies done on similar topics. The first one was a quantitative survey sent to students regarding their attitudes towards free speech ("Student Attitude" 2017). 
This study was similar because in schools, it is considered a safe space to talk about issues, like race. So, I modeled this specific study in correspondingly creating my student surveys. When creating my teacher survey, I modeled "A Study of Self-Censorship by School Librarians" which was written by Wendy Rickman, an associate professor at Arkansas State University. She specializes in ethics, education, and access. Rickman used a more quantitative approach to creating her surveys and gained qualitative reasoning from it. This study was focused on finding whether or not librarians would self-censor content and why that was the case (Rickman 2010). Since, this topic is similarly aligned with the information I was trying to gain from teachers, my teacher surveys were modeled after the questions in this study. These two studies led me to, therefore, use the mixed methods approach effectively.

The student survey was sent out during the AP Capstone survey date in FISD on December 11th, 2019. Whereas the teacher survey was sent out via email on January 27th, 2020. The general assumption that is being made is that high schools play a role in limiting or filtering racial discussions in school; this study, however, is focusing on how much and what school factors affect these discussions. Since the research is studying what factors and the extent to which the factors facilitate racial discussion in school, the mixedmethods approach is most effective in determining factors through quantitative data and conveys the scope of factors impacted through qualitative questioning. Similar to the survey, the analysis process also includes similar steps conducted when approaching conclusions through a mixed methodology.

\subsection{Survey Reasoning}

As previously stated, the design of the student survey was based on the mixed methods approach. For both surveys, by using Google forms and limiting free-response questions and number of questions this allowed respondents to navigate through the survey with efficiency. Furthermore, by using this internet application, you can study the data easier by curating the responses through an excel sheet. Additionally, by giving the surveys for students through the AP Capstone survey day, this will allow for the largest survey group without having to ask each high school individually for permission. For the teacher survey, I asked my AP Research teacher to send a mass email to all teachers at Reedy high school to take my survey. I included all teachers to be part of my survey because based on my student surveys, some students discuss race in a class that may not conventionally discuss this. I eventually ended up curating it so that the only data responses that I had received was from teachers that would conventionally talk about race. Because the study focuses on policies that affect comfort in a classroom context, for example, a math teacher may not have much to contribute to the topic. This was the easiest way for me to get the most quality responses for this survey.

Specifically looking at the first section of the survey, the inclusion of demographic related questions is vital. Since this survey brings about both qualitative and quantitative reasoning, demographics play a key role in starting any other key factors or limitations to address regarding my research question. Then the survey moves on to ask several questions regarding the respondent's several opportunities they have to conduct or participate in racial discussion within a school environment and their comfort during these situations. To make sure to not skew any data, I provided a wide variety of levels of comfort a person can feel, from a scale of 1-5, 5 being the most comfortable.

The overall set up of the teacher survey is very similar to the student survey. The first section begins with the demographics of the teacher. Then the questions move on to ask about the number of racial discussions conducted and what factors and school policies play a role in that. The length and time of the survey are still relevant to the requirements of the student survey. 
Mixed methods were integrated into both the data collection process and analysis. Along with the survey, the analysis looks for both quantitative and qualitative data. First, when looking at the survey results, the quantitative data that will be pulled from the teacher and student survey are certain factors that limit racial discussions. Specifically, in the student survey, a question asking about how the change in policies would help to facilitate racial discussion and address stereotypes. By looking at the most chosen answer or the answer people submitted through the "other" option, I can see which policy limits these discussions the most. Whereas in the teacher survey, the survey asked for specific policies from teacher respondents that restrict their ability to talk about race in a high school environment.

When analyzing qualitative data, the process can be much more complex. Qualitative data is analyzing the "to what extent" part of my research question. This required looking for common patterns and trends between people's level of comfort when talking about race and whether they felt school truly limited these discussions. Additionally, it is crucial to look at the survey as a whole, filtering questions, and understanding how much the respondents believe in what they are saying. The survey overall helps to understand the extent to which school policies and factors limit the facilitation of racial discussions regarding stereotypes etc. and its major implications.

\subsection{Limitations}

Though the survey approach was the best given the time and feasibility of the research, it comes with its limitations. Firstly, like all other survey data, the respondents may not be truthful, may be biased, or randomly answering the questions. This human error might skew the data of the survey and may not make it the most accurate representation. Also, my interpretation of data might differ from other people, especially when looking through a qualitative lens. So, to mitigate the effects of this, it is crucial to analyze the data with the least amount of bias as possible. When looking at the several policies that affect racial discussions in school, due to students' lack of knowledge in this area it might be hard to figure out certain policies. However, this can be tailored information to show that the lack of knowledge of policies, could be a possible issue that needs to be addressed to solve this problem. For future replication of research, some future limitations that could arise could be sample size. This, however, was not a limitation I faced since I sent my surveys through the AP Capstone program getting around 123 responses. While for my teacher surveys, I received 33 responses. Finally, I was only able to send my teacher survey to Reedy High School (one of the FISD schools) which may not represent all of FISD.

\section{Results}

\subsection{Student Survey}

After having sent out both surveys, a total of 123 responses were received from the student survey while 33 responses were received from the teacher survey. Looking specifically into student survey, the survey respondents were divided by grade so that there were 48 sophomores (10th graders), 62 juniors (11th graders), and 13 seniors (12th graders). To get an accurate conclusion from the student survey, I had to go through each student and create a table comparing frequency with Socratic seminars/and or curriculum-based discussions to comfort levels when talking about race. Table 1 shows how a portion of how my data was sorted for these 
questions. Three tables were created so that outside factors such as maturity of curriculum and age could be accounted for.

\section{Table 1.}

\begin{tabular}{|l|l|l|l|l|l|l|} 
Juniors & & \multicolumn{3}{|c|}{ Comfort Levels 5 being most comfotrable 1 being least for socratic } \\
\hline Respodents & Race & Ocurrence & & & \\
\hline 1 & Asian & Sometimes & & & \\
\hline 2 & Asian & Sometimes & & & \\
\hline 3 & Asian & Sometimes & & & \\
\hline 4 & Asian & Rarely & & & \\
\hline 5 & American & Inc Sometimes & & & \\
\hline 6 & Asian & Rarely & & & \\
\hline 7 & Black & Rarely & & & \\
\hline 8 & Asian/Black & Sometimes & & & \\
\hline 9 & Asian & Sometimes & & & \\
\hline 10 & Asian & Sometimes & & & \\
\hline 11 & Asian & Rarely & & & \\
\hline 12 & Asian & Always & & & \\
\hline 13 & Black & Often & & & \\
\hline
\end{tabular}

Furthermore, I also asked questions regarding how hesitant students were when discussing race and compared that to comfort levels during Socratic seminars and/or curriculum-based discussions about race. Analyzing the responses I found out that $22.28 \%$ responded with a 5 (ranking as the highest comfortable level), $35 \%$ responded with a 4, 29.3\% responded with a 3,13\% each responded with a 2 and 1 . This data proves that more than half of the respondents are more than comfortable providing their input in Socratic seminars and/or curriculum-based discussions.

Whereas looking at the frequency of Socratic seminars and/or curriculum-based discussions regarding race occurring in Frisco ISD schools, 38 students respond rarely, 47 said sometimes, 30 said often, and 2 people said never. While comparing alongside occurrences of Socratic seminars/and or curriculum-based discussions about race and comfort level percentages, there was no direct correlation. According to Table 1, it was $67.38 \%$ more likely that a person who chose "rarely", for the occurrence of race-based Socratic seminars/and or curriculum-based discussions, also chose a comfort level of 4 or 5 . Furthermore, this trend holds for "never", "sometimes", and "often", as all percentages are above 50\% for having chosen a higher comfort level during these seminars.

Overall, there is no clear connection between occurrences of race-based Socratic seminar/and or curriculumbased discussions and comfort levels during those discussions, however, one trend that was apparent in the survey was that people who put more input in Socratic seminars/and or curriculum-based discussions were less hesitant to talk about race in general and vice versa. If you compare the sample results of Table 1 to the sample results of Table 2, people who said they were not hesitant to talk about race rated a 3 or higher for comfort level in discussing race during Socratic seminars/and or curriculum-based discussions. On the contrary, the people who responded saying that they were/weren't hesitant talking about race, in summary, stated, that that was due to reasons outside of school such as, personality traits, upbringing, experience, race, friend groups, and even social beliefs/morals (as seen in Sample 1). 
Sample 1.

\begin{tabular}{|c|c|}
\hline Responses & $\begin{array}{c}\text { Are you hesitant to talk about race? Please } \\
\text { explain why and some reasons. }\end{array}$ \\
\hline Student 1 & $\begin{array}{l}\text { Since I'm white I am scared that I will be portrayed } \\
\text { as racist or incentive for my beliefs }\end{array}$ \\
\hline Student 2 & $\begin{array}{l}\text { "No because I'm black and people underestimate } \\
\text { the dscirimination people have faced in the past } \\
\text { and now." }\end{array}$ \\
\hline Student 3 & $\begin{array}{l}\text { "Not really. I am very comfortable in my own skin } \\
\text { but I am aware of others being critical or } \\
\text { upholding stereotypes about my race. Sometimes I } \\
\text { feel like some people reinforce the Indian } \\
\text { stereotypes and every now and then I feel } \\
\text { embarrassed by the actions of my own race in } \\
\text { tense situations (i.e school fights, in-class behaviors, } \\
\text { etc.). It's hard to explain my relationship with } \\
\text { people of my own race but I'm never hesitant to } \\
\text { talk about it." }\end{array}$ \\
\hline Student 4 & $\begin{array}{l}\text { "I am not hesitant to talk about race. I am generally } \\
\text { comfortable with my friends and my peers, which I } \\
\text { believe fosters an open discussion. I also think my } \\
\text { personality has something to do with it because } \\
\text { there are very few things, I am hesitant to talk } \\
\text { about." }\end{array}$ \\
\hline Student 5 & $\begin{array}{l}\text { "To some extent race is a sensitive topic t o talk } \\
\text { about in a school setting. If one thing wrong is said, } \\
\text { many people could get offended which is } \\
\text { something I do not want to risk." }\end{array}$ \\
\hline Student 6 & $\begin{array}{l}\text { I am hesitant to talk about race. As an East Asian at } \\
\text { Independence High there are not many other } \\
\text { students that have similar cultural experiences as } \\
\text { me. Thus, when I am having a "discussion about } \\
\text { race, it is usually talking about someone else's } \\
\text { culture (ex: participating in a discussion with my } \\
\text { friend group about an upcoming Indian holiday). } \\
\text { Sometimes they will make race-specific jokes such } \\
\text { as about colonization about their own race but } \\
\text { because I am a different race from them it is quite } \\
\text { awkward. I also do not want to accidently } \\
\text { mischaracterize their culture." }\end{array}$ \\
\hline
\end{tabular}


Table 2.

\begin{tabular}{|c|c|c|c|c|}
\hline Juniors & & Hesitant? & & \\
\hline Respodents & Race & Yes & No & Maybe \\
\hline 1 & Asian & & & \\
\hline 2 & Asian & & & \\
\hline 3 & Asian & & & \\
\hline 4 & Asian & & & \\
\hline 5 & \multicolumn{2}{|c|}{ American Indians } & & \\
\hline 6 & Asian & & & \\
\hline 7 & Black & & & \\
\hline 8 & Asian/Black & & & \\
\hline 9 & Asian & & & \\
\hline 10 & Asian & & & \\
\hline 11 & Asian & & & \\
\hline 12 & Asian & & & \\
\hline 13 & Black & & & \\
\hline
\end{tabular}

Finally to conclude the finding of the student survey, though curriculum-based policies do not play a direct factor on the limitation of a student's ability to partake in racial discussion, however according to my survey results portrayed that by exposing student more to racial stereotypes, biases, and racism $35.8 \%$ responded that it would help, $43.9 \%$ responded saying it might help, and $20.3 \%$ responded it would not help. This gives light to how the majority of students admit that by adding policies allowing students to interact more with the subject of race, there is a likely possibility student would become even more comfortable talking about the topic.

\subsection{Teacher Survey}

Now analyzing the teacher survey, the primary reason for this survey was to gain insight into policies and how the school handled the situation, but the data also conveyed something more. I took a more quantitative approach and summarized the most popular and frequent responses to get a general summary of this data to gain a first-hand perspective of this topic. First of all, one of the questions that I had asked the teachers was what policies or consequences prevents a teacher from delving into complex topics about race. The top policies or consequences that teachers had mentioned were job termination, legal actions (lawsuit and suing), media censorship, curriculum, and relationships with students portrayed in Responses I (which only displays a portion of the responses received).

\section{Responses 1.}

\begin{tabular}{|l|l|}
\hline Responses & $\begin{array}{c}\text { What may be some teacher consequence on } \\
\text { offending a student or parent when discussing } \\
\text { race etc.? }\end{array}$ \\
\hline Teacher 1 & $\begin{array}{l}\text { "Students/Parents are easily offended, so these } \\
\text { topics MUST be handled with care. In my classes, }\end{array}$ \\
\hline
\end{tabular}


where they are part of the curriculum, there is quite a bit of racial diversity and the students are respectful, so filtering is not often needed."

Teacher 2

"Anytime one confronts the majority who is in power you risk getting in trouble. The emperor wears no clothes, but doesn't like hearing about it. So as a teacher I have to be extra careful and precise about what I say and have a lot of facts to back up my argument. I am careful not to stereotype the majority in power as well. Nevertheless, the fear of offending the wrong student is there and the fear of blowback is real, even if the teacher does no wrong"

Teacher 3 "....at worst, quietly not being rehired next year because of "unprofessional behavior".......all that being said, our administration is generally quite reasonable and supportive of well-meaning teachers who are trying to raise awareness and encourage a safe conversation for all potential parties involved- I would suggest that the greater problem is with assorted extremist families who attack a placating administration..."

\section{Teacher 4} Written up, probation, forced to resign, fired all depending on the severity of it."

Teacher 5

"I think that depends entirely on the case and the offense.I think teachers will be supported by their administrators if presenting objective information that relates to the course they teach. I imagine that clear cases of racism by a teacher would carry a much stiffer penalty."

Teacher 6 "Loss of trust and respect and comfort for the student which has a huge impact on their learning. Depending on the severity of the offense, legal actions can be taken."

What can be incurred from the Response I is that some teachers fear the penalty while others do not. For example, if we look at the response of Teacher 2 states that it is true that teachers have fear when discussing race, whereas that response is contrasted by Teacher 4 . Teacher 4 states that though that may be true, within the school district the main issue at hand is regarding extremists' parent's quarrels with the administration. The several varying perspectives displayed by teachers proved that there are policies that restrict the extent to which a racial conversation regarding racial stereotypes and bias can reach. As stated by Teacher 2, most racial discussions within the curriculum must be backed up with several facts and arguments so that it is not sprouting offensive conversation.

In addition, I had also asked several questions talking about how teachers saw racial discussions in schools and how that coincided with the school policies. Several had said that they were unsure, but an overwhelming number of respondents (19 teachers) said that race was discussed in school (and a lot outside of as well) and how different races cause for unique experiences (revolving around equality of races) but doesn't focus on the current situations of race, racial stereotypes, along with bias and addressing those issues (as seen in Responses 
2 and Responses 3). Yet, it is also equally important to address that there are other factors such as parents that play a major role in this as well.

\section{Response 2.}

\begin{tabular}{|c|c|}
\hline Responses & $\begin{array}{l}\text { Do you think race, racial biases, and stereotypes } \\
\text { should be more discussed within the curriculum? } \\
\text { Why? }\end{array}$ \\
\hline Teacher 1 & $\begin{array}{l}\text { "Yes. We are all raised with biases, but it is within } \\
\text { our power to educate ourselves and make a choice } \\
\text { about how we want to interact with the world. The } \\
\text { school system is often the best way for students to } \\
\text { be exposed to new perspectives that are different } \\
\text { from those of their home unit. If these topics are not } \\
\text { discussed in school, the next best place for students } \\
\text { to see new perspectives is the internet. School is a } \\
\text { safer place to explore these topics than the internet } \\
\text { where you can see a lot of extreme thinking." }\end{array}$ \\
\hline Teacher 2 & $\begin{array}{l}\text { "Absolutely. I disagree with the idea of color } \\
\text { blindness as a method to fight racism. I believe that } \\
\text { it should be discussed from all perspectives. Our } \\
\text { curriculum shows clear political biases, and I rarely } \\
\text { hesitate to point them out." }\end{array}$ \\
\hline Teacher 3 & $\begin{array}{l}\text { "Yes. It is important that these conversations be had } \\
\text { with students and teachers in order to open the } \\
\text { minds of everyone. Also, so that everyone has a } \\
\text { chance to see and understand their biases, and } \\
\text { hearing someone else's input/story can give a } \\
\text { different (maybe even more real) perspective." }\end{array}$ \\
\hline Teacher 4 & $\begin{array}{l}\text { "Within the scope of my classes, I think it's already } \\
\text { balanced. Not every novel or story we read will } \\
\text { bring up the topic of race, but there are quite a few } \\
\text { works that bring up the topic. I can't speak about } \\
\text { other class subjects, as I'm not fully aware of the } \\
\text { course content. It would likely be too forced to have } \\
\text { race-related topics as part of a curriculum for } \\
\text { subjects like math, chemistry, etc." }\end{array}$ \\
\hline Teacher 5 & $\begin{array}{l}\text { "Yes but it has to be relevant and appropriate, not } \\
\text { forced" }\end{array}$ \\
\hline Teacher 6 & $\begin{array}{l}\text { "Yes. We do a disservice to our IBYOC } \\
\text { (Indigenous, Black, and youth of color) when we try } \\
\text { to deny them the entirety of their lived experiences } \\
\text { by saying we don't see color. Everyone has racial } \\
\text { bias, and we need to actively seek to interrupt them } \\
\text { and change them. Only by talking openly about race } \\
\text { and white privilege can we seek to change things. } \\
\text { Our textbooks were found to have been white }\end{array}$ \\
\hline
\end{tabular}


washed and conservative viewpoints overrode actual historical information in a recent NYT article. White teachers who don't want to address race are choosing to be complicit in this system of oppression."

Teacher 7 "It could be if we had more training and information."

Looking at Response II (a sample/summary of responses received), a majority of the teachers believe that in our school system, racial biases, stereotypes, and race needs to be further examined and discussed in the school environment. Teacher 1 states the repercussion of not talking about race in a safer environment in comparison to other platforms like the internet, is significant. Another interesting point is made by Teacher 6 who points out how in the textbooks used in FISD, they typically are "whitewashed" and portray "conservative viewpoints." As a result, the summary of responses received from the teachers show not only that race needs to be further embedded within the curriculum, they also shed light to the several policies or factors that limit this, which is primarily the colorblind curriculum. The colorblind concept is a recurring method of teaching seen in many curriculums (further discussed in the literature review). Based on the policies and limitations that are discussed by the responses, it seems as though FISD uses that approach when creating policies. Consequently, that could correlate as to why based on students' responses, resulted in feeling equal, but some responses felt they couldn't accept their cultural differences or talk about others.

\section{Responses 3.}

\begin{tabular}{|l|l|}
\hline Responses & $\begin{array}{c}\text { Any comments you would like to add about } \\
\text { school regarding race please add below. }\end{array}$ \\
\hline Teacher 1 & $\begin{array}{l}\text { "Students here in this time are more aware than ever } \\
\text { of the differences in culture and there is a real } \\
\text { opportunity for us to come together more as a } \\
\text { unified whole, but there is also a hidden racism that } \\
\text { is so ingrained into the culture that it sometimes } \\
\text { operates on an unconscious level. Through dialogue } \\
\text { we can start to identify these hidden biases that we } \\
\text { all have and work towards a better future." }\end{array}$ \\
\hline Teacher 2 & $\begin{array}{l}\text { "I have been at schools where racial tensions were } \\
\text { high but I believe that [FISD] High Schools does a } \\
\text { great job of integrating activities where students } \\
\text { encourage each other regardless of race." } \\
\text { "I would like to see more students demand that their } \\
\text { teachers have Diversity, Equity, \& Inclusion } \\
\text { training and that things like the district literature list } \\
\text { be overhauled to reflect the diverse student } \\
\text { population." }\end{array}$ \\
\hline Teacher 3 & $\begin{array}{l}\text { "I feel like Reedy is very healthy compared to } \\
\text { many environments, but even here there are racial } \\
\text { issues- but they are comparatively tame to the } \\
\text { national/state average." }\end{array}$ \\
\hline Teacher 4 & \\
\hline
\end{tabular}




\begin{tabular}{|c|c|}
\hline Teacher 5 & $\begin{array}{l}\text { "I think the big question to ask is how the school is } \\
\text { *actively* working to address racial issues. The real } \\
\text { measure of a school's effort is in how the school } \\
\text { engages students, staff, and community members in } \\
\text { ongoing discussions of race, not necessarily through } \\
\text { policy. I think the question you want to ask teachers } \\
\text { is whether or not they think the school and/or } \\
\text { district sees race as an issue worth addressing." }\end{array}$ \\
\hline Teacher 6 & $\begin{array}{l}\text { "We are in a very diverse district and a common } \\
\text { issue here is when "good" stereotypes are used in a } \\
\text { harmful manner. For example some students } \\
\text { experience pressure when they are struggling in a } \\
\text { class that they are stereotyped to do well in. They } \\
\text { can experience this pressure and negative comments } \\
\text { from teachers, friends, and their own families." }\end{array}$ \\
\hline Teacher 7 & $\begin{array}{l}\text { "there is not a right to not be offended or hear } \\
\text { differing opinions, so it is frustrating when } \\
\text { conversations that are critical to one's understanding } \\
\text { of the world are limited or censored." }\end{array}$ \\
\hline
\end{tabular}

The significance of response 3 depicts that FISD is a more diverse district in contrast to several others. Teachers 2, 4, and 6 believe that FISD due to its diversity does not require the need for racial integration. However, there is still a great number that contradicts the opposite view. Teacher 1 explains that though bias and stereotypes are not apparent they very much exist. Take note, there are several more responses than displayed above, which in summary are split evenly in the following views. Thus, since FISD is diverse people are more comfortable with other races, however, it is imperative to make sure that "unsaid" or "hidden" racial tensions are discussed.

In comparison to the student survey, this connects why students may be more comfortable about talking about race as society has become more accepting of the topic and why students may not be affected as much by racism. Furthermore, as teachers have responded, the race is talked about heavily within Frisco ISD, and since the school is so diverse a lot of students have become accustomed to racial equality. With that said, there is still a small amount of unspoken racial tension that still may be occurring, which we must take note of. If the colorblind method is being used in FISD school policies, that means that there will be a percent of teachers and students that will accept race equally, but self-censors themselves about more serious topics like racial distinctions, etc.

\section{Discussions}

\subsection{Implications}

As previously stated, there is no direct correlation between the occurrences of race discussions. However, we also found out that some teachers self-censor themselves, and if more policies including conversations 
regarding the current climate of the race were included, the overall knowledge of the topic would be expanded.

Though my study disproved my hypotheses, this brings several more things into question. The main one being, what may be the direct factors that affect students' comfort levels when discussing race? Amanda Barrasso, a writer and editor from the Pew Research Center, discusses the trend that "Americans turn to family and friend networks to talk about race and race relations. But who is likely to be having these conversations, with whom and how often depend at least in part on a person's racial and ethnic identity, age, education, and political affiliation..." (Barrasso 2019). This aligns with the conclusions of my research as to how education plays a role in racial discussions.

However, other more influential factors affect students' perception and comfort when talking about race. Amanda Barrasso does a survey study similarly aligned to mine with similar results in that, "Most black $(77 \%)$, white (74\%), Asian (70\%) and Hispanic (62\%) adults who ever have conversations about race say they are generally very or somewhat comfortable when the topic comes up" (Barrasso 2019). She then continues to assert how the most influential aspect of a person's comfort is the area that they were brought up in and the level of education they have. The higher a person's educational level the more comfort they have.

Furthermore, if they were brought up in a diverse region this plays a major role in how comfortable people are. So concerning the study I conducted, since Frisco's spread of students is so diverse this could play a large role in why most students were comfortable. Furthermore, since I studied high school students if the parameters were changed to middle school students the outcome may have been different.

Though no clear correlation was drawn, an interesting thing that came up is the possible use of the colorblind method. As seen in the results, there seemed to be a small yet apparent connection with the use of this method in FISD policies. According to a research paper by Dan French and Warren Simmons, "A colorblind approach flies in the face of that knowledge...the net result is that students of color, their experiences, and their perspectives become 'invisible' in the classroom" (Simmons 2015). When teachers employ this method, their intentions are typically to create an environment surrounded by equality however, as stated above they ignore the important distinctions of differing races. In connection with the results from the survey, regardless of the myriad of respondents who expressed comfort when talking about race, there was still a high percentage who were not comfortable. This could be due to the colorblind method in which they don't feel comfortable in identifying racial distinctions (aside from color) which explains why there was a high percentage of students who chose 3 as their comfort during discussions. With regards to answering the research question, this study portrays that though not a dictating force, school policies concerning race in the curriculum have some effect on improving conditions of student's comfort level. However, school policies play no significant role in negatively impacting the growth of students in this aspect.

\subsection{Limitations}

Another factor that explains the phenomenon of my results could be due to some time or limitations by parameters. To get the most results, discussed in the methodology, I had focused on AP Capstone students. However, the AP Capstone program did not reflect the level of diversity as the overall FISD statistics did. Most respondents in my survey were Asian and this could be a potential limitation. Furthermore, another prominent limitation is not including a parent or school board survey. Since it was concluded that several outside factors influence a student's ability to talk about race in high school, including more stakeholder's perspectives might have brought a more conclusive finding. However, due to the COVID-19 crisis occurring, I was unable to send these surveys to try to get a better understanding of my research topic. The reason for 
addressing this limitation is that should future studies be conducted; they can focus on trying to avoid the effects of this.

\section{Conclusions}

The results alongside the research of this study answered the research question in that there is no direct correlation between deterring the comfort levels of students and racial curriculum-based policies. However, some possible factors that could affect this are the upbringing of students and the use of the colorblind method. In addition, we found out that by improving FISD policies we could increase the depth of racial conversation that occurs. By "using curriculum and instruction that is explicit about race and the impact of racism in schools and society promotes school cultures in which students of color feel more of a sense of belonging and empowerment." (Simmons 15). Regardless, FISD proves to be a starting base or model for other schools to build upon because the presence of racial conversation is very high, along with great diversity, in comparison to other schools.

Since the conclusion of the study has been drawn and potential factors have been addressed. This study can serve as both a foundation for future studies with varying parameters and a foundation for a base of racial policies. As discussed above, this paper can sprout new studies. By addressing the limitations and changing the parameters of my study, other researchers can bring or expand on the conclusions brought from this study. They can address students outside the AP Capstone, study different locations, age groups, etc. and see the varying results. Since Frisco ISD has proven that their racial policies do not limit the growth of students' racial understanding. However, there are many other schools with less diversity or weaker policies, other school boards can use Frisco ISD as a base to create new and better policies.

\subsection{Proposed Solutions}

Though proven that Frisco ISD's policies are effective for the most part, there are some more things they could incorporate to further enhance these school programs for handling race in the curriculum. The multicultural night is an event that is a day to display cultures and teach students about different races in FISD. However, the turnout of the event is typically low and by making this event mandatory, all students can learn about other races, making them less receptive to bias and stereotypes. Another solution would be to incorporate more readings in English classes that talk about the racial current climate. Over the years, many books were taken from the curriculum (censored) due to its racial content. However, many students are unaware of the current situations of racism and should be further incorporated. Moreover, by decreasing the harsh punishments of racism prevention policies, this will allow open comfort when discussing more serious issues of race (Losen 2013). Keep in mind these are only a couple of the many plethora of solutions available.

In conclusion, Frisco ISD should focus on implementing policies that provide more exposure to race so that students can gain awareness and understanding of this issue. Though policies currently set in place don't limit a student's capacity to hold a racial conversation within the curriculum, by enforcing more policies that reveal the truths about race, biases, and stereotypes, this will allow students to gain knowledge and embrace diversity to its full potential. 


\section{References}

Anderson, Jill. “Addressing Racial Inequity in Curriculum and School Culture.” Harvard Graduate School of Education, 29 Aug. 2014, www.gse.harvard.edu/news/14/08/addressing-racial-inequity-curriculumand-school-cult ure. Accessed 15 May 2020.

A. Glasow, Priscilla. Fundamentals Of Survey Research Methodology. 1st ed., Mitre, 2005, pp. 1-28, https://www.mitre.org/sites/default/files/pdf/05_0638.pdf. Accessed 11 Jan 2020.

Barroso, Amanda. "How Often People Talk about Race with Family and Friends Depends on Racial and Ethnic Group, Education, Politics.” Pew Research Center, Pew Research Center, 25 June 2019, www.pewresearch.org/fact-tank/2019/06/25/how-often-people-talk-about-race-with-famil y-andfriends/. Accessed 29 Apr 2020. 
Blum, Lawrence. "Five Things High School Students Should Know About Race". Hepg.Org, 2012, https://www.hepg.org/hel-home/issues/28_6/helarticle/five-things-high-school-students-s houldknow-about. Accessed 29 Apr 2020.

“Frisco ISD Student Handbook” Frisco ISD, 2020, www.friscoisd.org/docs/default-source/resourcesinformation/frisco-isd-student-handboo k.pdf. Accessed 29 December 2019.

“Frisco ISD.” Frisco Independent School District - Home, 7 Jan. 2020, www.friscoisd.org/about/districtoverview/facts-figures. Accessed 29 December 2019.

Heim, Joe. “It Is America's Original Sin. So Why Haven't the Nation's Schools Done a Better Job of Teaching about Slavery?" The Washington Post, WP Company, 28 Aug. 2019, www.washingtonpost.com/education/2019/08/28/teaching-slavery-schools/?arc404=true. Accessed 29 April 2020.

"Historical Timeline Of Public Education In The US". Race Forward, 2006, https://www.raceforward.org/research/reports/historical-timeline-public-education-us. Accessed 10 Apr 2020.

"History Of Black Education". Www2.Kenyon.Edu, 2020, https://www2.kenyon.edu/Depts/Amerstud/blackhistoryatkenyon/Individual\%20Pages/Hi story\%20of\%20Black\%20Education.htm. Accessed 19 Apr 2020.

Losen, Daniel J. "Discipline Policies, Successful Schools, Racial Justice, and the Law." Race, Racism and the Law, July 2013, https://racism.org/index.php?option=com_content\&view=article\&id=1812:discipline-poli ciessuccessful-schools\&catid=195\&Itemid=155. Accessed 22 May 2020.

Rickman, Wendy. "SLR_Volume_13.Pdf.” American Association of School Librarians, 2010, http://www.ala.org/aasl/sites/ala.org.aasl/files/content/aaslpubsandjournals/slr/vol13/SLR _Volume_13.pdf\#page=168.Accessed 23 Sept. 2019. 